$\Phi=$

\title{
Dental anxiety - neglect of dental care
}

\author{
R. Sudhakara Reddy ${ }^{1 *}$, K. Ramya ${ }^{3}$, K. Pavani ${ }^{2}$, G. Subbarayudu ${ }^{4}$, N. Rajesh ${ }^{2}$, R. Sruthi ${ }^{2}$ \\ ${ }^{1}$ Professor and Head, Department of Oral Medicine and Radiology, Vishnu Dental College, Bhimavaram, Andhra Pradesh, India \\ ${ }^{2}$ Post Graduate, Department of Oral Medicine and Radiology Vishnu Dental College, Vishnupur, Bhimavaram, Andhra Pradesh, India \\ ${ }^{3}$ Assistant professor, Department of Oral Medicine and Radiology, GSL Dental College, Rajahmundry, Andhra Pradesh, India \\ ${ }^{4}$ Professor, Department of Prosthodontics, GSL Dental college, Rajahmundry, Andhra Pradesh, India \\ *Corresponding author E-mail:sudhakarareddyomr@gmail.com
}

\begin{abstract}
Background: The cause of delay in obtaining a dental care definitely depends on the individual's anxiety status at a dental set up. Anxiety is a state of delirium experienced by an individual. Nevertheless, this feeling of discomfort may hamper the quality of life of an individual.

Objectives:To assess the degree of dental anxiety and to assess the reason for dental anxiety

Methods: A total of 950 participants were enrolled into the present study. Data was collected using a questionnaire. The questionnaire consisted of two parts; the first part composed of items on demographic characteristics of the patient, and the second part included a questionnaire consisting of combination of Corah's Dental Anxiety Scale and Dental Fear Survey.

Results: In a total sample of 872 patients, 538 individuals were dentally anxious (mean DAS >9) of which 495 patients had a mean score of 9-12 (Mildly anxious); 30 patients had a mean score of 13-15 (Moderately anxious). Only a few subjects (13) were highly anxious (mean DAS > 15). When individual situation of anxiety was assessed, the population noted highest anxiety on feeling or seeing the anaesthetic needle followed by feeling of the vibrations of the drill and being seated in a dental chair.

Conclusion: As dental anxiety is a continuum, where to place the cut-off point is a crucial issue in research, which aims to compare subjects fearful of dentistry with those who are not. The validity of many measures has not been adequately assessed, perhaps because of the difficulty of identifying an external referent against which it may be tested. Evidence in the form of behavioral, physiological or cognitive characteristics should be considered to manage these dentally anxious individuals effectively in the dental office.
\end{abstract}

Keywords: Corah's Dental Anxiety Scale; Dental Anxiety; Dental Fear Survey.

\section{Introduction}

Dentistry is committed to ongoing research motivated by the need to improve the overall health of the patients. In this regard, everyday clinical practice has benefited from newer technologies and treatment approaches, which are concomitantly supported by awareness among public health. However, still there is a significant challenge in providing dental care due to the prevalence of dental anxiety (Hmud\& Walsh 2009). Anxiety in a true sense is an act of anticipation of danger, which is accompanied by restlessness, tension and other allied factors to an unidentifiable stimulus (Malvania\&Ajithkrishnan 2011). In case of dental operatory, anxiety is an important component of psychological suffering to the patients. Dental anxiety occurs preveniently without the presence of stimulus (Shrestha et al 2009). Fear is defined as a feeling of alarm or disquiet caused by the expectation of danger, pain, disaster or the like. Fear and anxiety towards a dentist are ranked as fourth among common fears (Ebtissam et al 2002).

Weiner and Sheehan classified dental anxiety into exogenous anxiety and endogenous anxiety based on the etiology. Exogenous anxiety occurs due to various reasons, including prior trauma, past dental experiences, low pain threshold. Symptoms in exogenous anxious patients occur in response to external stimuli. Endogenous anxiety occurs because of underlying medical disease, which may be due to metabolic or biochemical disturbance in central nervous system (Weiner 1989). As proposed by Doebling and Rowe, the five factors which have their influence on an individual's daily life are physiological, cognitive, behavioural, health and social. The prevalence of dental disease is increasing among patients with dental anxiety. Dentally anxious individuals avoid dental health care services, and usually they are house bound and rely on selfremedies to relieve dental pain (Astrom Anne et al 2011).

\section{Materials and methods}

Ethical approval for carrying out the present cross sectional survey was obtained from research ethics committee of a dental institution in Bhimavaram town, West Godavari district, Andhra Pradesh, India. The study was carried out for a period of 6 months. A total of 950 subjects were included in the study based on convenience sampling. The sample represents whole of the population which includes both urban and rural areas as the study was conducted in a dental institution where all kinds of dental services will be offered. Patients waiting in the outpatient department of Oral Medicine and Radiology were included in the study and written informed consent was obtained from each subject. The inclusion criteria emphasizes that individuals should be above the age of 10 years and all the patients should have past dental experience with treatment done at least for once and all the dental procedures were done by the same team. Exclusion criteria included the patients who were uncooperative, not willing to participate volun- 
tarily in the study and those who filled the questionnaires incompletely.

The purpose of the study was explained to each participant, and information was retrieved using a questionnaire. The present study used a single questionnaire coupled with both Corah's dental anxiety scale and Dental Fear Survey. Corah's dental anxiety scale has been used in the present study since it is a traditional and most commonly applied questionnaire to assess dental anxiety. Literature supports that the translated version of corah's DAS has proven to be valid and reliable measure of dental anxiety in culturally diverse populations (Shrestha et al 2009). The questionnaire consisted of two parts; the first part composed of items on demographic characteristics of the patient, and the second part included a questionnaire consisting of combination of Corah's Dental Anxiety Scale (DAS) and Dental Fear Survey (DFS). DAS questionnaire contained four items in a multiple choice format addressing subjective response to a particular dental situation. The four items include a) anticipating a visit to a dental clinic, b) waiting in the dentist's office for treatment, c) drilling of teeth, and d) scaling of teeth. For every item, there are five possible responses ranging from 1 to 5 . So for each item a maximum score of $5 \mathrm{can}$ be obtained. Hence for the entire scale, the total possible maximum score is 20. Depending upon the DAS scores, Dental anxiety was grouped into 'mild', 'moderate', and 'severe' with DAS scores of 9-12, 13-15, >15 respectively (Shrestha et al 2009). Dental Fear Survey, proposed by Kleinknecht, is used to identify the specific and unique answers to a variety of stimuli correlated to the dental activities (Marginean\&Filimon 2011). In the present study, the original DFS questionnaire was modified according to the ease of the patient and ease of methodology. The original DFS questionnaire consists of 20 questions, whereas in, the present study it was limited to 13 items of the original questionnaire. The self-reported combination questionnaire consisting of both Corah's DAS and DFS were translated into local regional language (Telugu) and were used. The questionnaire was pilot tested; reliability and va- lidity was done by using Cronbach's alpha. The value obtained was 0.86 indicating a more valid questionnaire. SPSS version 11 was used for data analysis. The data was not normally distributed henceforth non parametric tests were used for analysis. The relation between dental anxiety and age was assessed by using Kruskal-Wallis test. Mann-Whitney U test was used to compare gender variations and dental anxiety scores in different anxiety situations. Level of statistical significance was set at $\mathrm{p}=.05$.

\section{Results}

Of the 950 questionnaires forms given to eligible participants, 70 were not returned and eight were incompletely filled. Hence a total of 872 answered questionnaire forms were analyzed for the assessment of anxiety. The prevalence of dental anxiety in the present study was found to be $56.4 \%$. Table 1 , Fig. 1 shows age and sex distribution of the total sample. Among the total sample, highest percentages of individuals $(33.6 \%$ ) are within the age range of 21-30 years where the dental needs are high. In the entire study group there were 463 males and 409 females.

Table 1: Age and Sex Distribution of the Total Sample

\begin{tabular}{llll}
\hline Age & $\begin{array}{l}\text { Sex } \\
\text { Male }\end{array}$ & Female & Total \\
\hline 10-20 years & 44 & 34 & $78(8.9 \%)$ \\
21-30 years & 170 & 123 & $293(33.6 \%)$ \\
31-40 years & 81 & 91 & $172(19.7 \%)$ \\
41-50 years & 73 & 91 & $164(18.8 \%)$ \\
51-60 years & 43 & 43 & $86(9.9 \%)$ \\
61-70 years & 36 & 23 & $59(6.8 \%)$ \\
>70 years & 16 & 4 & $20(2.3 \%)$ \\
Total & 463 & 409 & 872 \\
\hline
\end{tabular}

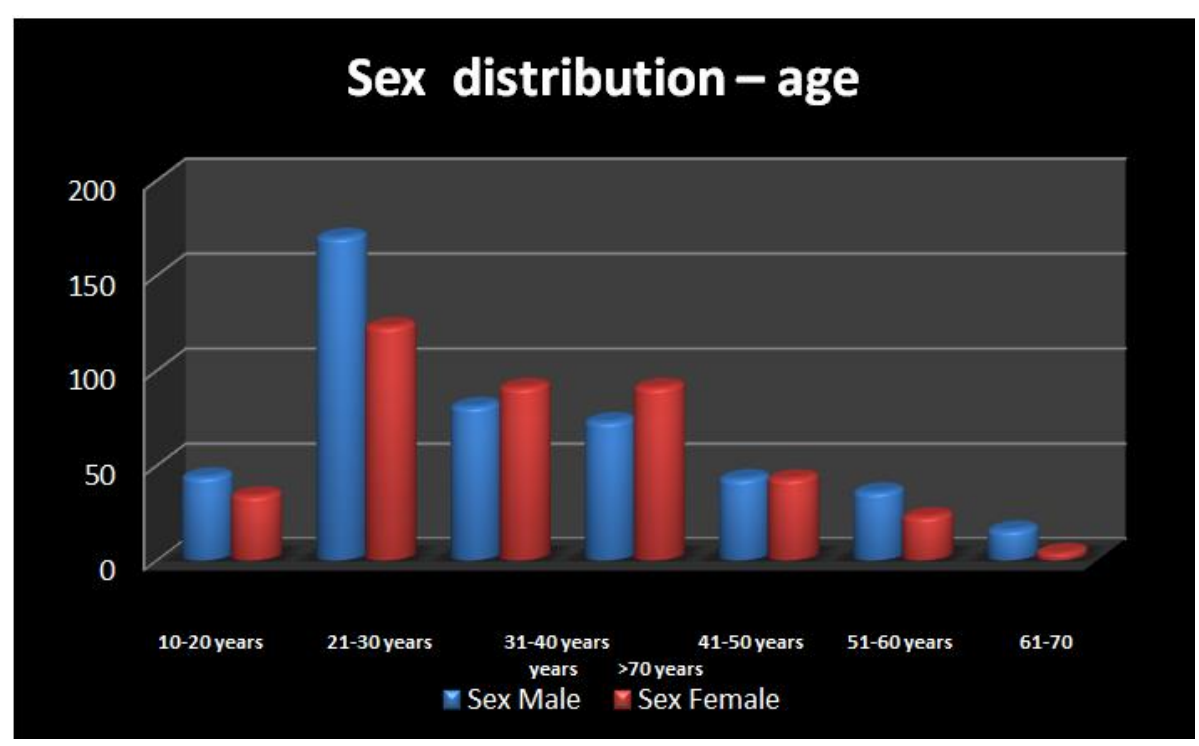

Fig. 1: Age and Sex Distribution of the Total Sample

Mean anxiety levels and number of individuals in each group were analysed (Table 2, Fig. 2). Subjects in whom the mean DAS score $>9$, were considered dentally anxious. In the total sample of 872 patients, 538 individuals were dentally anxious (mean DAS $>9$ ) of which 495 patients had a mean score of 9-12 (Mildly anxious); 30 patients had a mean score of 13-15 (Moderately anxious). Only a few subjects, 13 were highly anxious (mean DAS > 15).

Gender variation among the dentally anxious individuals was assessed using Mann Whitney U test. (Table 3) Females had a greater mean score of 12.32 when compared to males 11.2 which is highly significant $(\mathrm{p}$ value $<0.001)$.
Table 2:Mean Anxiety Levels and Number of Individuals in Each Group

\begin{tabular}{ll}
\multicolumn{2}{c}{ Table 2:Mean Anxiety Levels and Number of Individuals in Each Group } \\
\hline Mean DAS & Number of individuals \\
\hline$<9$ & 334 \\
$9-12$ & 495 \\
$13-15$ & 30 \\
$>15$ & 13 \\
\hline
\end{tabular}




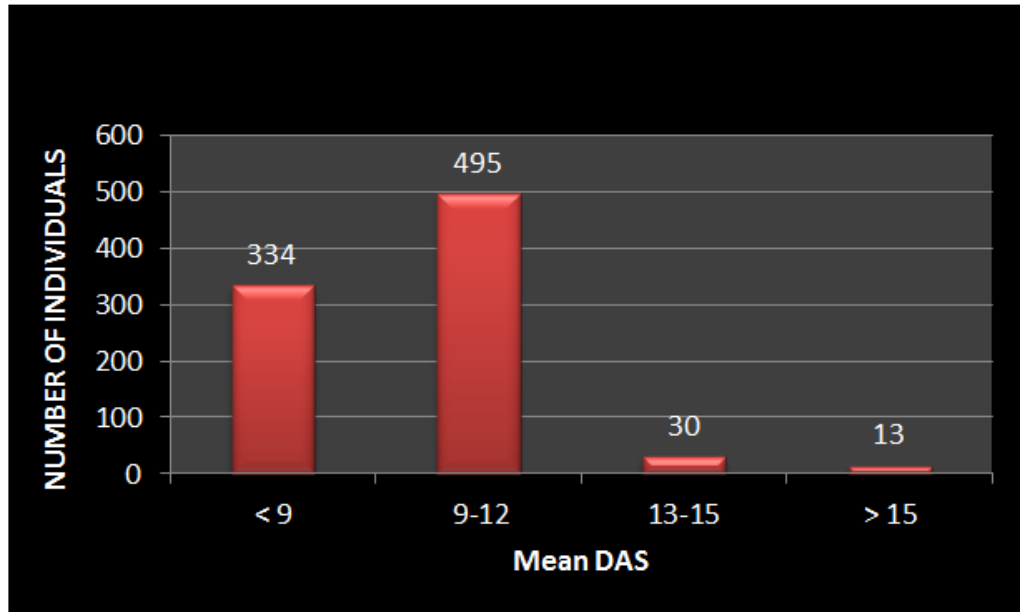

Fig. 2: Mean Anxiety Levels and Number of Individuals in Each Group

Table 3:Gender Variation among the Dentally Anxious Individuals

\begin{tabular}{llll}
\hline Gender & No. of individuals & Mean DAS score & Significance \\
\hline Female & 278 & 12.32 & \\
Male & 260 & 11.20 & $0.001\left(\right.$ HS $\left.^{*}\right)$ \\
\hline
\end{tabular}

*Highly Significant

The relationship between dental anxiety and age was assessed using Kruskal-Wallis test. When age was correlated with anxiety, there was a mixed pattern (Table 4). As the age group of subjects increased from 10-20 years to 51-60 years, the anxiety scores gradually increased from 11.4 to 12.4 . Subjects who were above 60 years have shown a gradual decline in anxiety with a least anxiety level of 10.84 in patients above 70 years of age. The difference in anxiety levels showed no statistical significance with a pvalue of 0.161 .

\begin{tabular}{llll}
\multicolumn{5}{c}{ Table 4:Anxiety Levels in Correlation with Age } \\
\hline $\begin{array}{l}\text { Age } \\
\text { group }\end{array}$ & $\begin{array}{l}\text { Number of individu- } \\
\text { als }\end{array}$ & $\begin{array}{l}\text { Mean DAS } \\
\text { SCORE }\end{array}$ & $\begin{array}{l}\text { Significance } \\
\text { p-value }\end{array}$ \\
\hline $10-20$ & 48 & 11.40 & \\
$21-30$ & 181 & 11.80 & \\
$31-40$ & 106 & 12.20 & \\
$41-50$ & 101 & 12.00 & \\
$51-60$ & 53 & 12.40 & $0.161\left(\mathrm{NS}^{*}\right)$ \\
$61-70$ & 37 & 11.40 & \\
$>70$ & 12 & 10.84 & \\
\hline
\end{tabular}

Table 5: Dental Anxiety Situations

\begin{tabular}{llll}
\hline $\begin{array}{l}\text { Dental Anxiety Situa- } \\
\text { tion }\end{array}$ & $\begin{array}{l}\text { Number Of } \\
\text { Individuals }\end{array}$ & $\begin{array}{l}\text { Mean Das } \\
\text { Score }\end{array}$ & Significance \\
\hline $\begin{array}{l}\text { Making an appoint- } \\
\text { ment for dentist }\end{array}$ & 23 & $11.00(1.12)$ & \\
$\begin{array}{l}\text { Approaching a den- } \\
\text { tist's office }\end{array}$ & 34 & $11.24(0.92)$ & \\
$\begin{array}{l}\text { Waiting in the dentists } \\
\text { waiting room }\end{array}$ & 42 & $11.48(1.34)$ & \\
$\begin{array}{l}\text { Being seated in dental } \\
\text { chair }\end{array}$ & 56 & $12.18(1.64)$ & \\
$\begin{array}{l}\text { Smell of dentist's } \\
\text { office }\end{array}$ & 42 & $11.86(1.36)$ & \\
$\begin{array}{l}\text { Seeing the dentists } \\
\text { walk in office }\end{array}$ & 36 & $11.64(1.68)$ & \\
$\begin{array}{l}\text { Seeing the anaesthetic } \\
\text { needle }\end{array}$ & 58 & $12.68(1.18)$ & \\
$\begin{array}{l}\text { Feeling the needle } \\
\text { injected }\end{array}$ & 64 & $12.6(2.2)$ & p-value; \\
$\begin{array}{l}\text { Seeing the drill } \\
\text { Hearing the drill }\end{array}$ & 52 & $11.84(1.40)$ & 0.016* \\
$\begin{array}{l}\text { Feeling the vibrations } \\
\text { of drill }\end{array}$ & 48 & $11.00(1.46)$ & \\
$\begin{array}{l}\text { Having your teeth } \\
\text { cleaned }\end{array}$ & 48 & $12.24(1.48)$ & \\
\hline
\end{tabular}

\section{Discussion}

Anxiety is quite common in anyone planning to visit a dentist or undergoing treatment in dental office. Anxiety may occur either with any external stimuli or stimulus originating within the body (Dobros et al 2014). Dental anxiety causes suffering in people of all ages with different socio environmental conditions, which ultimately results in poor oral health by avoidance of regular dental health care (Tunc et al 2005).

Dental anxiety leads to neglect of dental care causing increased dental problems making the patient reach dentist who further increases patient's original fear resulting in an ongoing cyclic process (Ebtissam et al 2002). In this study, the dental anxiety prevalence was $56.4 \%$, which is in variation with studies conducted by Thomson et al (Malvania\&Ajithkrishnan 2011) who reported the prevalence of anxiety to be $46 \%$, Koleoso et al (Koleoso et al 2014) who reported prevalence of about $10.7 \%$ in Nigeria's population, which is less than the present study population. The variation in dental anxiety prevalence could be attributed to the sociocultural differences between study populations, variations in the measure of dental anxiety and cut-off scores used to distinguish between those who were dentally anxious and those who were not. In a study conducted by Stabholz et al, it was identified that anxiety was higher among subjects in an age group 35-44 years [Stabholz\&Peretz 1999, Locker et al 2001). This observation is in contrast to the results of our study where anxiety was highest among 51-60 years with a p-value of 0.161 , which is not statistically significant. Bhalla et al (Bhalla et al 2013) reported that males between the age group 15 to 23 and 24 to 33 belonged to fairly anxious group and only slight anxiety was observed in a higher age group (44 to 53 years). On the other hand, females were found to be very anxious at the higher age group of 24-33 years and 34-43 years. This correlation can be attributed to the need of dental care, which was highest among this group of individuals because of awareness towards dentistry and for an esthetic purpose.

Deva priya et al (Deva priya et al 2012) in her study showed that there is no statistical significant difference between the age groups in relation to their mean total score, which is in contrast to the present study where the dental anxiety was highest among 51-60 years age group.

Dobros et al (Dobros et al 2014), Koleoso et al (Koleoso et al 2014) in their studies stated that the mean dental anxiety level was higher in females when compared to males who are in accordance to the present study. This is due to the fact that females readily confess their feelings or anxiety (Malvania\&Ajithkrishnan 2011). Other factors like lower threshold levels in females, more selfreporting nature are the causes for their anxiety. In the present study, the difference in anxiety between males and females is highly significant $(\mathrm{P}=0.000)$. 
In contrast to the present study Tunc et al (Tunc et al 2005), Deva priya et al (Deva priya et al 2012) showed no difference in the anxiety levels between males and females. There is a mixed relationship between age and dental anxiety. The highest DAS scores was in the age group 51-60 years (12.40) followed by the age group 31-40 years (12.20) and after 60 years the score was declining. This is in accordance to Shreshta et al (Shreshta et al 2009), Koleoso et al (Koleoso et al 2014), Bhalla et al (Bhalla et al 2013). Variation in the number of individuals in each group or a general fact that fear and phobia decreases with age is the factor for the mixed pattern seen between age and anxiety (Hagglin et al 2000, Udoye et al 2005). This decline of dental anxiety with age could be attributed to age dependent cerebral deterioration, factors like extinction or habituation and adaptive resignation towards the inevitable (Koleoso et al 2014).

In the present study, seeing and feeling the anaesthetic needle were the most anxiety provoking stimuli with DAS score -12.68 , followed by feeling the vibrations of drill (12.24) and being seated in a dental chair (12.18) with a $\mathrm{p}$ - value (significant) 0.016 (Table 5). This finding is in accordance to the study conducted by Deva priya et al (Deva priya et al 2013), Naidu et al (Naidu \&Lalwah 2010), Sghaireen et al (Sghaireen et al 2013). These findings suggest the need for the use of 4S RULE in managing patients who aims to reduce triggers of stress - Sight, Sound, Sensations, and Smells. Use of atraumatic restorative procedures, chemical caries removal, laser therapies in the dental office would help in coping the stress (Hmud\& Walsh 2009).

\section{Conclusion}

Inconsistency of the existing data and varied results documented in the literature, prompted us to conduct the present study. So, we would like to conclude that valid assessment of anxiety levels in the patients who are in need of dental treatment will definitely benefit both the clinician and patient in rendering them the best dental services and also will be able to curtail the myths surrounding the dental experiences.

\section{Competing interests}

Authors have declared that no competing interests exist.

\section{References}

[1] Hmud R, Walsh LJ (2009). Dental Anxiety: Causes, Complications And Management Approaches. Journal of Minimum Intervention in Dentistry 2(1), 67-78.

[2] Malvania EA, Ajithkrishnan CG (2011). Prevalence and socio demographic correlates of dental anxiety among a group of adult patients attending a dental institution in Vadodara city, Gujarat, India. Indian

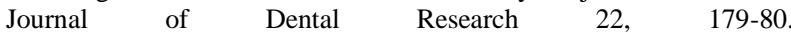
http://dx.doi.org/10.4103/0970-9290.79989.

[3] Shrestha A, Rimal J, Rao A, Sequeira PS, Doshi D (2009). Dental anxiety among patients visiting a teaching dental hospital in Mangalore, India. Journal of Nepal Dental Association 10, 12-15.

[4] Ebtissam M. Al-Madi, Hoda Abdel Latif (2002). Assessment of denta fear and anxiety among adolescent females in Riyadh, Saudi Arabia. Saudi Dental Journal 14, 77-81

[5] Weiner AA (1989). Differentiating Endogenous Panic/Anxiety Disorders from Dental Anxiety. Anesthesia Progress 36, 127-139.

[6] Astrom Anne N, Skaret Erik, Haugejorden Ola (2011). Dental anxiety and dental attendance among 25-year-olds in Norway: time trends from 1997 to 2007. BioMedCentral Oral Health 11, 10. http://dx.doi.org/10.1186/1472-6831-11-10.

[7] IoanaMarginean, Letitia Filimon (2011). Dental Fear Survey: A validation study on the Romanian population. Journal of Psychological and Educational Research 19 (2), 124-138.

[8] Dobros K, Hajto-Bryk J, Wnęk A, Zarzecka J, Rzepka D (2014). The level of dental anxiety and dental status in adult patients. Journal of International Oral Health 6, 11-14.

[9] Tunc EP, Firat D, Onur OD, Sar V (2005). Reliability and validity of the Modified Dental Anxiety Scale (MDAS) in a Turkish population.
Community Dentistry and Oral Epidemiology 33, 357-62. http://dx.doi.org/10.1111/j.1600-0528.2005.00229.x.

[10] Koleoso ON, Akhigbe KO (2014). Prevalence of Dental Anxiety and the Psychometric Properties of Modified Dental Anxiety Scale in Nigeria. World Journal of Dentistry 5, 53-59. http://dx.doi.org/10.5005/jp-journals-10015-1258.

[11]Locker D, Thomson WM, Poulton R (2001). Onset and pattern of change in dental anxiety in adolescence and early adulthood: a birth cohort study. Community dental health 18, 99-104.

[12]Stabholz A, Peretz B (1999). Dental anxiety among patients prior to different dental procedures. International Dental Journal 49, 90-94. http://dx.doi.org/10.1111/j.1875-595X.1999.tb00514.x.

[13]Bhalla A, Singh SB, Sujata, Singh A, Choudhary A (2013). SelfAssessment of Dental Anxiety in Patients Visiting Comprehensive Rural Health Service Project. Journal of Depression and Anxiety 2, 137.

[14]Appukuttan D, Datchnamurthy M, Deborah SP, Hirudayaraj GJ, Tadepalli A and Victor DJ (2012). Reliability and validity of the Tamil version of Modified Dental Anxiety Scale. Journal of Oral Science 54, 313-320. http://dx.doi.org/10.2334/josnusd.54.313.

[15] Appukuttan D, Tadepalli A, Priyanka K Cholan, SubramanianS, MythreyiVinayagavel (2013). Prevalence of Dental Anxiety among Patients Attending a Dental Educational Institution in Chennai, India A Questionnaire Based Study. Journal of Oral Health and Dental Management 12, 289-294.

[16]Hagglin C, Hakeberg M, Ahlqwist M, Sullivan M, Berggren U (2000). Factors associated with dental anxiety and attendance middle-aged and elderly women. Community Dentistry and Oral Epidemiology 28,451-60. http://dx.doi.org/10.1034/j.1600-0528.2000.028006451.x.

[17]Udoye CI, Oginni AO, Oginni FO (2005). Dental Anxiety among patients undergoing various dental treatments in a Nigerian teaching hospital. Journal of Contemporary Dental Practice 6, 91-98.

[18]RS Naidu, S Lalwah (2010). Dental Anxiety in a Sample of West Indian Adults. West Indian Medical Journal 59, 567.

[19]Sghaireen MG, Zwiri A, Ibrahim A. Alzoubi, Sadeq M. Qodceih, and Mahmoud K. AL- Omiri (2013). Anxiety due to Dental Treatment and Procedures among University Students and Its Correlation with Their Gender and Field of Study. International Journal of Dentistry, 15.Thakurdesai PA, Kole PL \&Pareek RP (2004), Evaluation of the quality and contents of diabetes mellitus patient education on Internet. Patient Education and Counseling 53, 309313.http://dx.doi.org/10.1155/2013/647436. 